\title{
Mobility of Source Zone Heavy Metals and Radionuclides: The Mixed Roles of Fermentative Activity on Fate and Transport of $\mathrm{U}$ and $\mathrm{Cr}$
}

\author{
William Apel (INL), Brent Peyton (MSU), Robin Gerlach (MSU), Brady Lee (INL)
}

\section{Research Objectives:}

Predicting the potential migration of metals and radionuclides from waste pits and trenches will require understanding the effects of carbon and electron flow through these environments. Important aspects of this flow include the physiological activity of cellulolytic and non-cellulolytic fermentative microbial populations, as well as the subsequent activity of metal and radionuclide reducing bacteria. The activity of subsurface fermentative microbial populations is significantly understudied even though these organisms can affect contaminant migration by at least two mechanisms. In the first mechanism, products of the fermentation process can act as chelators for metals and radionuclides increasing their transport through underlying geological media. The second mechanism is the reduction and immobilization of metals and radionuclides since some fermentative bacteria have been shown to directly reduce metals and radionuclides, while their fermentation products can provide carbon and energy for respiratory metal reducing bacteria that can also reduce oxidized metals and radionuclides.

Our research will elucidate mechanisms of carbon and electron flow through natural environments using simulated cellulosic waste constituents. To this end, our research has three major goals: (1.) to characterize the production of fermentable substrates and low molecular weight organics from organic debris in low level waste by the activity of cellulolytic and non-cellulolytic fermentative microbial populations and study their effect on the mobility of $\mathrm{U}(\mathrm{VI})$ and $\mathrm{Cr}(\mathrm{VI})$, (2.) understand the response of microbial communities to carbon and electron flow through these natural and simulated environments, and (3.) use this information to develop updated conceptual models for carbon and electron flow in waste systems and the associated effect of $\mathrm{Cr}(\mathrm{VI})$ and $\mathrm{U}(\mathrm{VI})$ transport in the subsurface. Information generated will help to better identify and predict the potential for migration of metals and radionuclides such as $\mathrm{U}(\mathrm{VI})$ and $\mathrm{Cr}(\mathrm{VI})$ from DOE waste sites. The proposed multidisciplinary project will provide observations and experimental approaches for coupled biological, chemical and hydrogeological processes controlling $\mathrm{U}(\mathrm{VI})$ and $\mathrm{Cr}(\mathrm{VI})$ transport in the subsurface.

\section{Research Progress and Implications:}

The proposed research will be accomplished in 3 Tasks: Task 1 will serve to develop an understanding of the fate of $\mathrm{Cr}(\mathrm{VI})$ and $\mathrm{U}(\mathrm{VI})$ in the presence of cellulose as the only source of carbon and electrons in batch and biofilm reactor experiments. In Task 2, intact sediment cores will be retrieved from LLW disposal facility within the Radioactive Waste Management Complex (RWMC) at the INL and geochemically characterized before culturable and unculturable microorganisms will be identified. The effect of $\mathrm{Cr}$, U, and carbon sources (cellulose, sugars, and fermentation products) on the activity of defined mixed communities derived from the soil cores will be conducted in batch and sediment flow reactors containing a well-defined representative mineral mixture (e.g., quartz and ferrihydrite). In Task 3 , the observations developed in Tasks 1 and 2 will be expanded into a full multi-component biogeochemical reactive transport system and used to observe the effects of a cellulose fermenting community on the transport and transformation of $\mathrm{U}$ and $\mathrm{Cr}$.

This report summarizes research performed during the first year of our two year project. Research addressing Task 1 is designed to test the hypothesis that cellulolytic microbial communities degrade cellulosic waste materials to mono- and polysaccharides as well as low molecular weight organic acids and alcohols while reducing $\mathrm{U}(\mathrm{VI})$ and $\mathrm{Cr}(\mathrm{VI})$, and that these processes can result in increased or decreased mobility of metals and radionuclides sorbed to LLW.

Sampling of surrogate low level wastes to support all three research tasks for the project occurred in August. The Cold Test Pit (CTP) located within the Radioactive Waste Management Complex (RWMC) at the INL was selected for sampling because the original design of the pit was well suited with our research objective. The CTP was designed to test the implementation of novel remote waste characterization and retrieval operations; for this reason, identification of waste forms within the pit were well documented. 
Two locations within the original Cold Test Pit South (CTPS) were selected for sampling based upon the proportion of combustible materials in the cells. The random dumped drums and stacked boxes were selected based upon the reported contents and various site employees' experiences. A geophysical survey using both electromagnetic induction and ground penetrating radar was performed to identify possible hazards and suggest possible sampling locations. Only the cell containing stacked boxes produced samples containing surrogate waste materials.

A 2 3/4" diameter direct push soil coring tool (AMS PowerProbe, American Falls, ID) was used to collect samples from an interval of 8' to 16' below the graded cap. This interval was selected based upon the observation that surrogate waste materials could regularly be found compacted toward the bottom of the pit. Cores were collected in PVC liners that had been washed in sodium hypochlorite bleach (500 ppm hypochlorite), rinsed in distilled water, dried, and UV irradiated for 6 hours. Upon retrieval, samples were placed into coolers, packed on ice and shipped back to the laboratory. Cores were cut and extruded within 24 hours of retrieval. The cores were pared and sectioned using flame-sterilized tools. All work was performed within a laminar flow hood to reduce the probability of contamination.

Sampling locations within the core were selected to represent environmental conditions above, within, and below the waste zone. Replicates of approximately 10 to 30 grams (wet weight) of soil were collected, packaged and shipped on ice to collaborators via overnight delivery. Samples for enrichment of cellulose degrading microbial populations were stored at $4^{\circ} \mathrm{C}$ and were cultured within 2 days of collection. Samples for nucleic acid extraction and for use in later column experiments were immediately frozen at $80^{\circ} \mathrm{C}$.

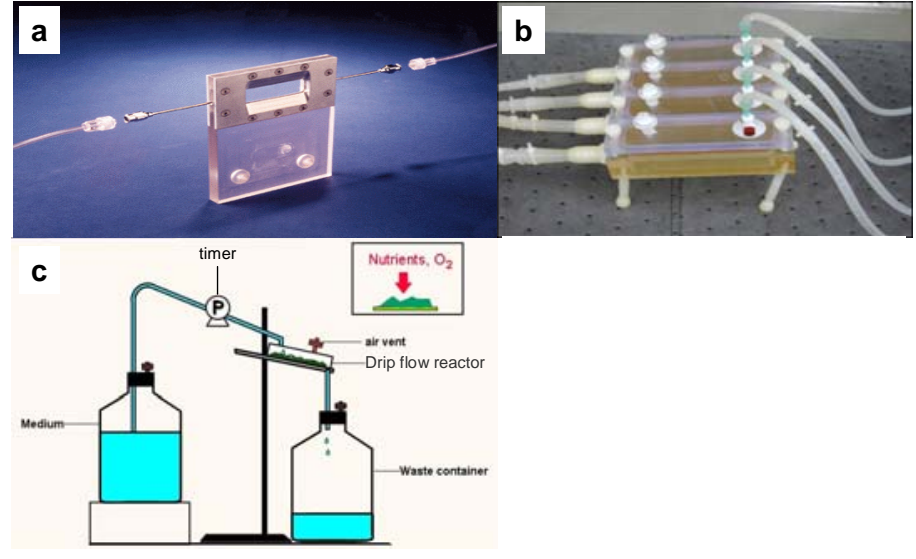

Figure 1. Biofilm reactors and setup; (a) biofilm flow cell for studies under saturated conditions, (b) drip flow reactors for unsaturated flow conditions, and (c) schematic of drip flow reactor operation.
For the initial phase of Task 1, efforts have resulted in bacterial and fungal enrichments and isolates from samples from the CTP at the RWMC at the Idaho National Laboratory. Biofilms of cellulose utilizing bacteria (Cellulomonas sp. strain ES6, isolated from DOE's Hanford site) and Clostridium thermocellum have been established in different reactors (Figure 1). Chromatographic methods involving ion chromatography with conductivity detection and high performance liquid chromatography with mass spectrometric detection to measure cellulose degradation products such as mono- and disaccharides and short chain fatty acids and alcohols have been (fatty acids) or are being (sugars and alcohols) established. Sorption isotherms of chromium and uranium on different cellulose materials (filter paper, microcrystalline cellulose, methyl cellulose) are being developed. Quantification of $\mathrm{Cr}(\mathrm{VI})$ is performed spectrophotometrically using diphenylcarbazide, $\mathrm{U}(\mathrm{VI})$ is determined using a kinetic phosphorescence analyzer and total $\mathrm{Cr}$ and $\mathrm{U}$ can be determined using Inductively Coupled Plasma (ICP) Mass Spectrometry (MS).

\section{Planned Activities}

During FY-07, Task 1 will continue as batch studies are performed to screen growth conditions for optimal cellulose degradation and metabolite production. Following optimization, flow through studies using biofilm reactors will be used to investigate spatial and temporal variation in cellulose utilization and their effect on metal mobility by different bacterial species and communities. Identification of microorganisms indigenous to the CTP through clone libraries and phylochip analysis will be performed as part of Task 2 . In addition, batch experiments will be performed using a designed community consisting of fermentative microorganisms as well as microbes capable of $\mathrm{Cr}(\mathrm{VI})$ and $\mathrm{U}(\mathrm{VI})$ reduction. These experiments will be 
important in generating data for development of experimental models. Finally, Task 3 will use small columns to understand the ability of microbes from soil taken from the CTP to degrade cellulose, and monitor the effect of breakdown products from the cellulose on $\mathrm{Cr}(\mathrm{VI})$ and $\mathrm{U}(\mathrm{VI})$ transport and reduction. Liquid effluent from columns containing soil and cellulose material (Kimwipes/cellulose filters) will be used to determine the effect of cellulose breakdown products on transport in defined mineral phases such as hematite, goethite, hydrous ferric oxide, etc. These experiments will be important for determining the effect of water saturated conditions on metal and radionuclide transport in defined geological media.

\section{Information Access}

Recent Presentations:

Field, E.K. , P. Haun, R. Gerlach, B.M. Peyton, W.A. Apel, and B.D. Lee (2006): The Influence of Cellulose Utilization on Metal and Radionuclide Mobility and Reduction. Poster Presentation at the 6th INRA Subsurface Science Symposium, Moscow, ID, September 25-27, 2006

Publications:

Viamajala, S., W. A. Smith, R. K. Sani, W. A. Apel, J. N. Petersen, A. L. Neal, F. F. Roberto, D. T. Newby, and B. M. (2007) Peyton. Isolation and Characterization of Cr(VI) Reducing Cellulomonas spp. from Subsurface Soils: Implications for Long-Term Chromate Reduction. Biores. Technol. 98:612-622. 